\title{
Chronic alcoholic skeletal muscle myopathy: a clinical, histological and biochemical assessment of muscle lipid
}

\author{
D SUNNASY, SR CAIRNS, F MARTIN, G SLAVIN, TJ PETERS \\ From the Division of Clinical Cell Biology and Section of Histopathology, MRC Clinical Research Centre, \\ Harrow, Middlesex
}

SUMMARY Muscle biopsy samples were analysed from five control subjects, four patients with mild to moderate fibre atrophy and four patients with severe atrophy. Patchy increase in lipid was noted with oil red $\mathrm{O}$ staining but there was no consistent association of lipid with selective fibre types. Ultrastructural studies demonstrated lipid droplets both subjacent to the sarcolemma and between fibrils.

Quantitative analysis showed that the increased lipid was solely due to excess triglyceride. GLC analysis of free and esterified acids was performed. The profiles were essentially similar for the $\vec{\emptyset}$ phospholipid and free fatty acid fractions. The triglyceride fraction showed a decrease of myristate, stearate and linoleate with an increase in oleate and arachidate in the alcoholic tissue ${ }_{0}$ compared with control. The cholesteryl ester fraction showed an increase in palmitate with a decrease in stearate and oleate in the alcoholic muscle.

The accumulation of lipid correlated with mean daily alcohol consumption but not with degree of atrophy suggesting that the two processes probably had different pathogenic mechanisms.

Chronic skeletal muscle myopathy, independent of peripheral neuropathy, is now well recognised in alcoholic patients. Several reports have commented on the increased skeletal muscle lipid in these patients at the ultrastructural level.' However, there has been no comprehensive biochemical analysis of these lipids. We have therefore studied the skeletal muscle lipids in a group of chronic alcoholics with skeletal myopathy and compared them with biopsies from patients with histologically normal muscle. Clinical and histological findings were correlated with a qualitative and quantitative assessment of skeletal muscle lipid with recently developed microanalytical techniques. ${ }^{2}$

\section{Material and methods}

Eight alcoholics who had histological evidence of skeletal myopathy and who had been drinking at least $100 \mathrm{~g}$ ethanol daily for at least three years were studied. Control specimens came from seven patients under investigation for symptoms sugges-

Accepted for publication 28 February 1983 tive of muscle disease but in whom subsequent官 investigation revealed no histological evidence of myopathy. A full clinical assessment of the patients? was made with particular reference to muscle weakness and ethanol consumption. Ethanol intake was assessed by patient enquiry and confirmed, where $\delta$ possible, by a cohabitant.

After an overnight fast, biopsies were obtained $\mathrm{O}$ with a modified Bergström needle $(4.5 \mathrm{~mm}$ diame- $\rightarrow$ ter) from the vastus lateralis at a standard site in the mid thigh. ${ }^{3}$ The procedure was performed under N local anaesthesia with an incision through the skin and deep fascia. All biopsies were taken within the $\tilde{O}$ first five days of patient hospitalisation. A portion, $\mathcal{\omega}$ approximately $10 \mathrm{mg}$, of the fresh biopsy was stored at $-20^{\circ} \mathrm{C}$ in $0.15 \mathrm{~mol} / 1 \mathrm{NaCl}$ for lipid analysis. Theo remaining tissue was processed for light and electron $\varnothing$ microscopy.

LIPID ANALYSIS

A portion of the muscle biopsy was blotted and $\stackrel{\mathbb{D}}{\Phi}$ rapidly weighed on a torsion balance. The tissue was $\stackrel{\Omega}{\varrho}$ homogenised at $4^{\circ} \mathrm{C}$ in $0.75 \mathrm{ml}, 0.15 \mathrm{~mol} / 1 \mathrm{NaCl}$ by 15 strokes of a Duall homogeniser (Kontes Glass $\Omega$ 
Table 1 Summary of clinical, pathological and biochemical data of patients studied

\begin{tabular}{|c|c|c|c|c|c|c|c|c|}
\hline Patient & Sex & Age (yr) & $\begin{array}{l}\text { Atrophy score } \\
\text { (type II fibres) }\end{array}$ & $\begin{array}{l}\text { Muscle } \\
\text { weakness }\end{array}$ & $\begin{array}{l}\text { Mean ethanol } \\
\text { consumption } \\
\text { during preceding } \\
\text { year (g/day) }\end{array}$ & $\begin{array}{l}\text { Muscle } \\
\text { triglyceride } \\
\text { (رmol/mg DNA) }\end{array}$ & $\begin{array}{l}\text { Type II muscle } \\
\text { fibre area (\%) }\end{array}$ & $\frac{\text { Weight }}{\text { Height }^{2}}$ \\
\hline $\begin{array}{r}1 \\
2 \\
3 \\
4 \\
5 \\
6 \\
7 \\
8 \\
9 \\
10 \\
11 \\
12 \\
13 \\
14 \\
15\end{array}$ & $\begin{array}{l}\mathbf{F} \\
\mathbf{F} \\
\mathbf{M} \\
\mathbf{M} \\
\mathbf{F} \\
\mathbf{M} \\
\mathbf{M} \\
\mathbf{M} \\
\mathbf{F} \\
\mathbf{F} \\
\mathbf{M} \\
\mathbf{M} \\
\mathbf{M} \\
\mathbf{M} \\
\mathbf{F}\end{array}$ & $\begin{array}{l}50 \\
34 \\
47 \\
38 \\
33 \\
34 \\
68 \\
43 \\
63 \\
45 \\
61 \\
44 \\
38 \\
57 \\
62\end{array}$ & $\begin{array}{r}5 \\
34 \\
51 \\
102 \\
117 \\
120 \\
142 \\
171 \\
223 \\
325 \\
344 \\
570 \\
584 \\
680 \\
1080\end{array}$ & $\begin{array}{l}0 \\
0 \\
0 \\
0 \\
0 \\
0 \\
0 \\
0 \\
++ \\
+ \\
++ \\
++ \\
+ \\
+ \\
++\end{array}$ & $\begin{array}{r}0 \\
150 \\
0 \\
0 \\
120 \\
30 \\
0 \\
200 \\
160 \\
200 \\
100 \\
160 \\
200 \\
200 \\
150\end{array}$ & $\begin{array}{r}6.9 \\
30 \cdot 3 \\
33 \cdot 6 \\
14 \cdot 1 \\
17.5 \\
10 \cdot 9 \\
11.4 \\
59.7 \\
41.0 \\
96 \cdot 0 \\
71 \cdot 6 \\
57.2 \\
57.0 \\
80.4 \\
55.0\end{array}$ & $\begin{array}{l}47 \cdot 9 \\
41 \cdot 6 \\
46 \cdot 2 \\
46 \cdot 0 \\
38 \cdot 1 \\
48 \cdot 0 \\
44 \cdot 4 \\
37 \cdot 2 \\
27 \cdot 4 \\
33 \cdot 0 \\
44 \cdot 4 \\
41 \cdot 6 \\
35 \cdot 2 \\
35 \cdot 7 \\
33 \cdot 2\end{array}$ & $\begin{array}{l}26 \cdot 8 \\
22 \cdot 1 \\
23 \cdot 4 \\
18 \cdot 8 \\
19 \cdot 0 \\
22 \cdot 4 \\
27 \cdot 6 \\
23 \cdot 2 \\
22 \cdot 1 \\
22 \cdot 5 \\
22 \cdot 4 \\
24 \cdot 6 \\
20 \cdot 6 \\
28 \cdot 1 \\
18 \cdot 8\end{array}$ \\
\hline
\end{tabular}

Co. Vineland, NJ, USA). An aliquot of $0.25 \mathrm{ml}$ homogenate was taken for DNA estimation ${ }^{4}$ and the remainder used for lipid extraction.

Total phospholipid, free fatty acid, triglyceride and free and esterified cholesterol were separated by thin layer chromatography and quantified, with the use of an internal standard, by specific chemical microassays. ${ }^{2}$ Fatty acid esters of the major lipids were transmethylated and measured by gas liquid chromatography. ${ }^{5}$ Although we were unable to measure total esterified cholesterol by the chemical method, gas liquid chromatography was sufficiently sensitive to determine the proportions of various fatty acid esters in the cholesteryl ester fraction.

\section{LIGHT MICROSCOPY}

Muscle biopsies were processed as previously described. ${ }^{6}$ Sections were studied with a variety of stains including haematoxylin and eosin, oil red $\mathbf{O}$ and myosin $\mathrm{Mg}^{++}$-ATP-ase, $\mathrm{pH} 9.4{ }^{7} \mathrm{Mg}^{++}$ ATPase sections were studied with a Magiscan image analysis system ${ }^{8}$ combined with an interactive computer programme to enable determination of atrophy factors for each fibre type. ${ }^{9}$

\section{Results}

Individual results are summarised in Table I with patients ordered according to type II fibre atrophy score. An atrophy score greater than 150 in men and 200 in women is considered abnormal and indicative of significant type II fibre atrophy. ${ }^{9}$ All patients who had been drinking at least $100 \mathrm{~g}$ ethanol daily had an abnormal atrophy score and all, except patient 8 , exhibited muscle weakness. There was no correlation between muscle triglyceride and atrophy score. However, a highly significant positive correlation was found between muscle triglyceride content and ethanol consumption (Fig. 1). All patients were clinically well nourished with no overt signs of vitamin deficiency. The Quetelet index $\frac{\text { weight }}{\text { height }^{2}}\left[\mathrm{~kg} / \mathrm{m}^{2}\right]$ ) was calculated for each patient and provides further evidence of their nutritional status [normal range (20$\left.\left.25 \mathrm{~kg} / \mathrm{m}^{2}\right)\right] .^{10}$

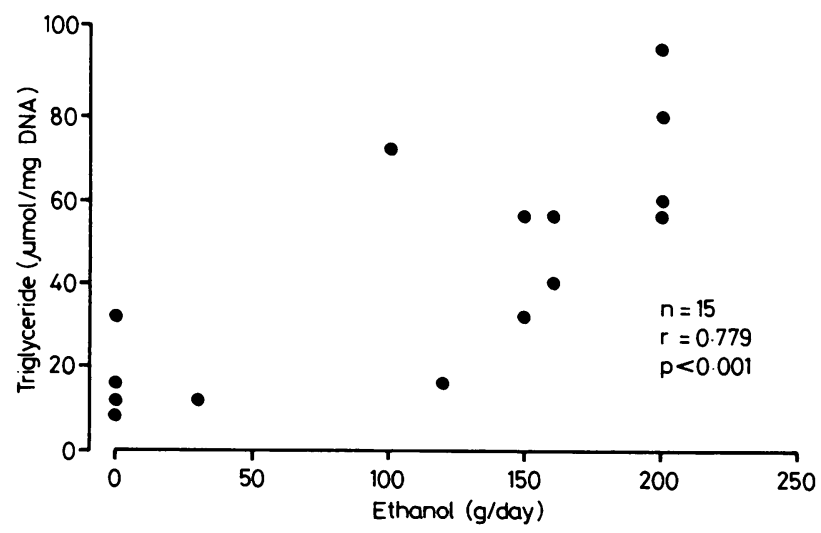

Fig. 1 Graph correlating ethanol consumption with muscle triglyceride for all patients $(n=15)^{11}$. 


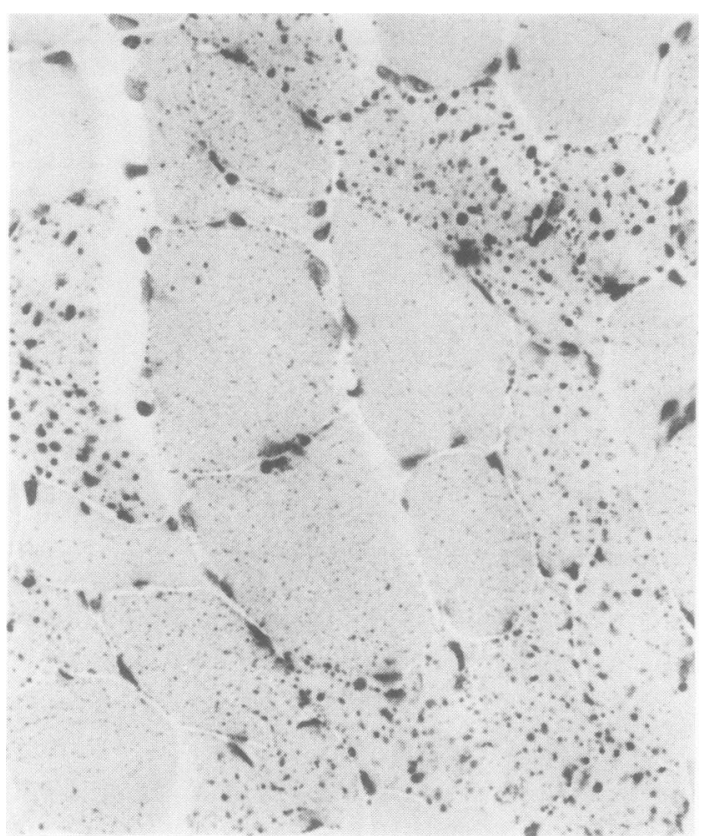

Fig. 2 Section of alcoholic myopathic tissue stained for lipid with oil red $O$. Variable distribution of lipid can be seen in many fibres. $\times 380$.

\section{MICROSCOPY}

Staining with oil red $\mathrm{O}$ demonstrated an excess of lipid droplets between and within fibres (Fig. 2). Ser $\overrightarrow{\vec{s}}$ ial sections to determine the localisation of lipid within fibres usually demonstrated a random distribution of lipid in both fibre types. However, in some biopsies it was apparent that there was a prefe $-\overline{\mathrm{\phi}}$ rential accumulation of lipid within non-atrophic type I fibres. At the ultrastructural level the lipides droplets accumulate between myofibrils and adja $\overrightarrow{0}$ cent to the sarcolemma (Fig. 3).

\section{MAJOR LIPID CLASSES OF MUSCLE}

Results are summarised in Table 2. In control tissue $50 \%$ of the muscle lipid was phospholipid, $25 \%$ tri. glyceride, $18 \%$ free fatty acid and $4 \%$ cholesterol No cholesteryl ester was detected by the technique which has a sensitivity of $<0.1 \mu \mathrm{mol} / \mathrm{mg} \mathrm{DNA}_{\circ}^{\infty}$ Alcoholics with myopathy showed an increase in? total lipid that was entirely accounted for by triglyceride. Concentrations of free fatty acids and free cholesterol were similar to controls and, althoughtotal phospholipid appeared to be decreased in myopathic tissue, the difference did not reach statis tical significance. Results of the lipid ester analysio for moderate and severe myopathy were grouped together since the findings in both groups were simi lar.

Fig. 3 Electron micrograph of alcoholic myopathic tissue. Lipid droplets can be seen immediately subjacent to the sarcolemma and between selected fibrils $\times 13750$.

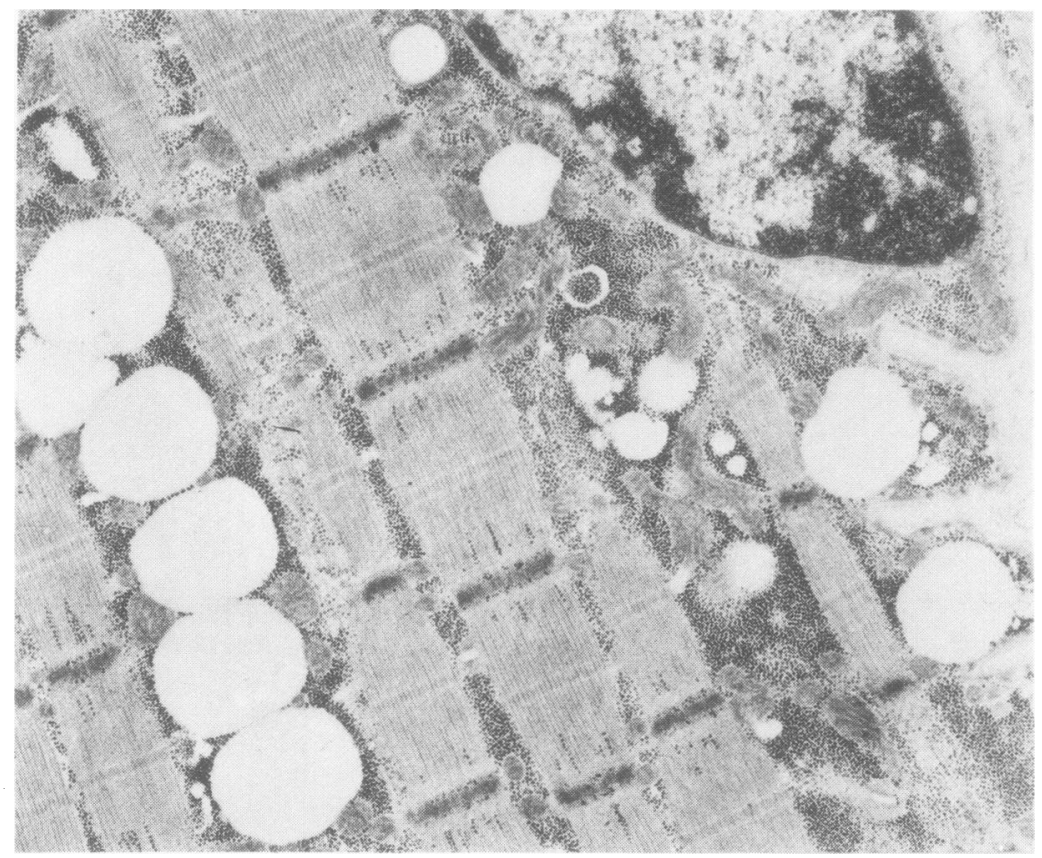


Table 2 Measurement of major lipids in human quadriceps muscle

\begin{tabular}{|c|c|c|c|c|c|}
\hline & Cholesterol & Free fatty acid & Triglyceride & Phospholipid & Total lipid \\
\hline $\begin{array}{l}\text { Controls } n=7 \\
\quad(\text { atrophy score }<150)\end{array}$ & $2.55 \pm 0.36$ & $11.8 \pm 2.2$ & $17 \cdot 8 \pm 3 \cdot 6$ & $33.5 \pm 4.5$ & $65.7 \pm 6.4$ \\
\hline $\begin{array}{l}\text { Moderate alcoholic myopathy } n=4 \\
\text { (atrophy score } 150-400 \text { ) }\end{array}$ & $2.33 \pm 0.43$ & $9.78 \pm 1.43$ & $67 \cdot 1 \pm 9 \cdot 9^{* * *}$ & $22 \cdot 3 \pm 2 \cdot 37$ & $101 \pm 12 \cdot 0^{*}$ \\
\hline $\begin{array}{l}\text { Severe alcoholic myopathy } n=4 \\
\text { (atrophy score 400-1200) }\end{array}$ & $2.47 \pm 0.30$ & $13.0 \pm 0.5$ & $62 \cdot 4 \pm 5 \cdot 2^{* * *}$ & $25 \cdot 0 \pm 5 \cdot 1$ & $108 \pm 9 \cdot 2^{* *}$ \\
\hline
\end{tabular}

Lipid expressed as mean \pm SEM $(\mu \mathrm{mol} / \mathrm{mg}$ DNA).

Statistical analysis by Student's $t$ test: ${ }^{*} p<0.01 ;{ }^{* *} p<0.0025 ;{ }^{* * *} p<0.0005$

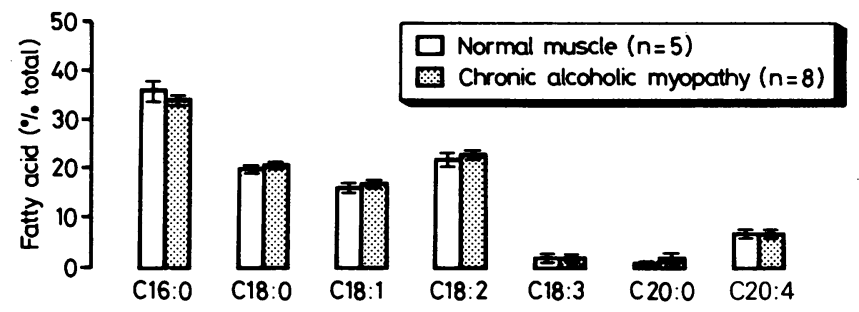

Fig. 4 Phospholipid fatty acid composition of normal and myopathic tissue. Results show mean $\pm S E M$ for five control and eight myopathic samples.

PHOSPHOLIPID FATTY ACID ESTERS (FIG. 4)

The major phospholipid fatty ester was palmitate (16:0) which contributed approximately $35 \%$ of the total fatty acid esters. The proportion of arachidonate $(20: 4)$, approximately $10 \%$, was highest in this lipid fraction. Proportions of all the phospholipid fatty acid esters in myopathic tissue were similar to those found in normal muscle.

The double bond index:saturated fatty acid ratio for myopathic tissue was not significantly different from normal muscle, 1.59 and 1.62 , respectively. This ratio is obtained by dividing the double bond index, that is, the sum of the products of the percentage of each unsaturated fatty acid and the number of double bonds by the percentages of saturated fatty acids.

FREE FATTY ACIDS (FIG. 5)

Palmitate (16:0) was the major free fatty acid comprising approximately $60 \%$ of the total. Except for the proportion of oleate, which was significantly diminished in the alcoholic group, the proportions of free fatty acids were similar in both patient groups.

TRIGLYCERIDE FATTY ACID ESTERS (FIG. 6)

In contrast to the other lipid classes, oleate (18:1) was the major triglyceride fatty acid ester, comprising approximately $40 \%$ of the total fatty acid esters. Several significant differences were found in the proportions of fatty acid esters between myopathic and normal muscle. Proportions of myristate (14:0), stearate (18:0) and linolenate (18:3) were significantly diminished and there was a significant increase in the proportions of palmitate (16:0), oleate (18:1) and arachidate (20:0) in the alcoholic group.

\section{CHOLESTERYL ESTERS (FIG. 7)}

There were differences in proportions of some fatty acid esters between myopathic and normal muscle. The proportion of palmitate (16:0) in myopathic tissue was markedly greater than that found in normal muscle whereas proportions of stearate (18:0) and oleate $(18: 1)$ were diminished.

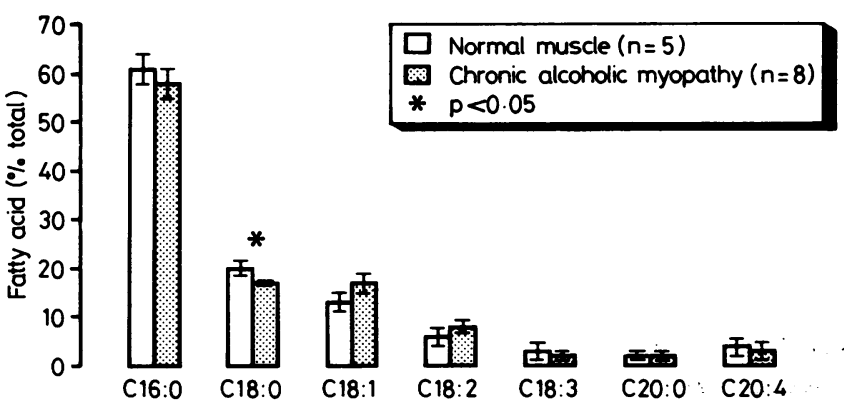

Fig. 5 Free fatty acid composition of normal and myopathic tissue. Results show mean \pm SEM for five control and eight myopathic samples; statistical analysis by Student's t test. 


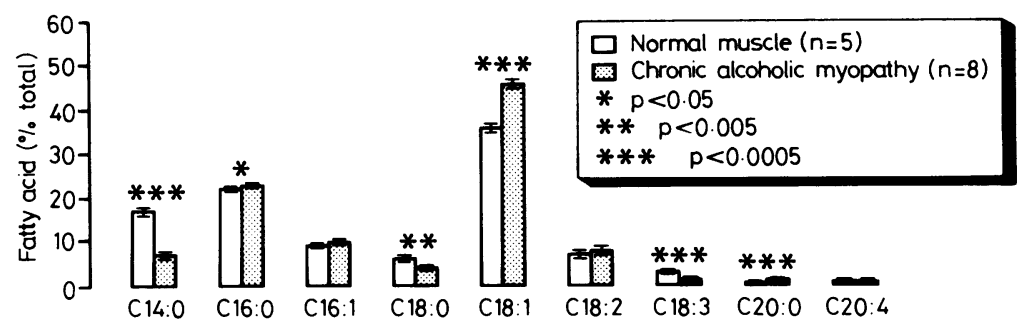

Fig. 6 Triglyceride fatty acid composition of normal and myopathic tissue. Results show mean $\pm S E M$ for five control and eight myopathic samples; statistical analysis by Student's $\mathrm{t}$ test.

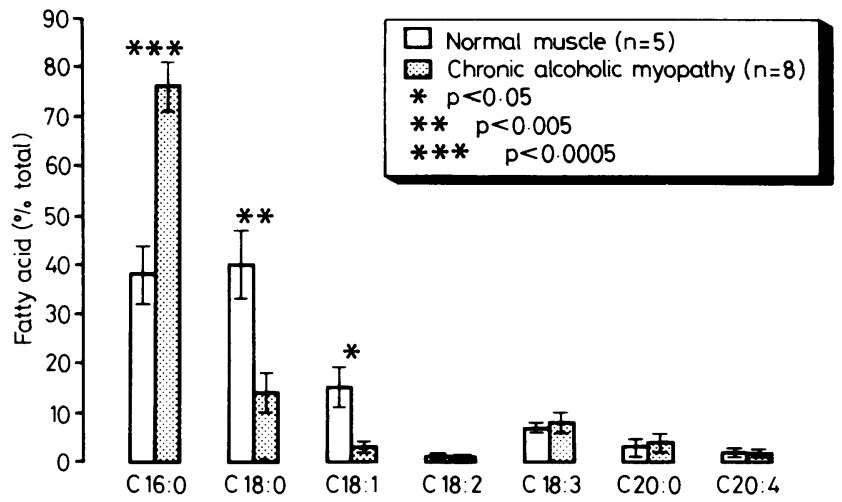

Fig. 7 Cholesteryl ester fatty acid composition of normal and myopathic tissue. Results show mean \pm SEM for five control and eight myopathic samples; statistical analysis by Student's t test.

\section{Discussion}

This study has demonstrated that triglyceride is the major accumulating lipid in skeletal myopathy associated with chronic alcoholism and that there are differences in the fatty acid composition of the triglyceride and esterified cholesteryl fractions in normal and myopathic tissue. We found no differences in the proportions of free fatty acids nor phospholipid fatty acid esters. Triglyceride accumulation correlated with ethanol consumption but not with the degree of type II fibre atrophy suggesting that lipid accumulation was not directly related to fibre damage.

There was a highly significant decrease in the proportions of linolenate, stearate and myristate esters of the triglyceride fraction and a significant increase in the proportions of oleate and palmitate. This depletion of some fatty acid esters is relative to the proportion found in normal muscle and does not indicate an absolute depletion since we found an overall increase of muscle triglyceride in myopathic tissue. In contrast to linolenate, the other essential fatty acid linoleate was not decreased in myopathic muscle. It is unlikely that the decrease in linolenate is due to a technical artefact since proportions of other triglyceride unsaturated fatty acids were either greater or similar to that found in normal muscle. Oxidation would have affected other unsaturated

fatty acids leaving the saturated fraction intact and thus increasing their proportion.

Experimental studies have demonstrated that $\stackrel{\mathbb{D}}{\not}$ ethanol interferes with the active transport of $\overrightarrow{\overrightarrow{0}}$ sodium and potassium ions by striated muscle ${ }^{12}$ but it seems unlikely that uptake of linolenate, which probably occurs by diffusion,,$^{13}{ }^{14}$ should be impaired when linoleate concentrations are unchanged. The $\bar{O}$ two series of essential fatty acids, $\omega 6$ and $\omega 3$, are derived from linolenic and linoleic acids and there is 3 . no interconversion between the two series. The increase in endogenously synthesised triglyceride 3 fatty acid esters, palmitate, oleate and arachidate, is 0 probably secondary to the slight but significant decrease in linolenate. In contrast to triglyceride, o the proportion of the cholesteryl linolenate was unchanged and oleate decreased. Since we were 0 unable to quantify total cholesteryl ester we cannot $N$ say whether absolute amounts of individual fatty acids in this lipid fraction differed between myopathic and normal muscle.

A number of pathophysiological explanations can be offered for the reported changes in triglyceride. $\stackrel{\oplus}{+}$ Firstly, the accumulation of triglyceride in 0 myopathic tissue might be due to increased activityo of the enzymes involved in its synthesis. Howeverब despite some evidence for this in hepatic triglyceride $\mathbb{D}$ accumulation,,$^{15}$ there is no evidence that this occurs in muscle. Ultrastructural observations have sug- 
gested that mitochondrial damage occurs in alcoholic myopathy. ${ }^{16}$ Since fatty acid oxidation occurs in mitochondria, such damage provides an alternative explanation for the triglyceride accumulation, particularly in type I fibres. However, despite these ultrastructural changes, studies of mitochondrial marker enzyme activities in these patients have indicated no defect of certain functions of this organelle. ${ }^{17}$ It is therefore possible that the pathogenesis of triglyceride accumulation in the type I mitochondrial-rich fibres differs from that in the type II fibres which are deficient in mitochondria relying almost exclusively on anaerobic glycolysis as an energy source.

An accurate assessment of the essential fatty acid intake by our patients was not established. It is possible but unlikely that the relative linolenate depletion seen in myopathic muscle is a reflection of either low dietary linolenate or malabsorption of linolenate. Hepatic triglyceride analysis of these alcoholic patients has shown similar alterations in the proportions of fatty acid esters to that seen in muscle triglyceride, although both linolenate and linoleate hepatic triglyceride esters were decreased. ${ }^{18}$

The cellular pathogenesis of alcoholic myopathy is unknown. Although there is a primate model for liver injury induced by chronic alcohol ingestion ${ }^{19}$ no adequate model for alcoholic myopathy exists. Unlike the liver, appreciable metabolism of ethanol does not occur in muscle and therefore it is not possible to invoke metabolic changes directly resulting from ethanol oxidation as cause for the muscle injury. Studies of isolated muscle preparations have demonstrated several metabolic defects induced by ethanol, ${ }^{20}$ for example, diminished sarcolemma transport of sodium, potassium and calcium ions, ${ }^{12} 21$ inhibition of protein synthesis, ${ }^{22}$ inhibition of fatty acid oxidation ${ }^{23}$ and inhibition actin-myosin association. ${ }^{24}$ Perkoff suggested that the initial pathological process of intracellular oedema resulted from increased sarcolemma permeability. ${ }^{25}$ Ethanol or acetaldehyde has been shown to inhibit the $\mathrm{Na}^{+}$, $\mathrm{K}^{+}$-activated ATPase of cardiac and skeletal muscle membrane in a dose-dependent and reversible manner with concentrations of ethanol that are achieved in vivo. ${ }^{26}$ Several membrane-bound enzymes including $\mathrm{Na}^{+}, \mathrm{K}^{+}$-activated ATPase are known to be affected by changes in membrane lipid composition. ${ }^{27}$ Our data showing concentrations of cholesterol, total phospholipid and phospholipid esters similar to normal tissue suggest that muscle membrane composition is unaltered in chronic alcoholic myopathy. Clearly further studies on the pathogenesis of both the muscle atrophy and the triglyceride accumulation are indicated.
We are grateful Dr AJ Levi for permission to study his patients and to Ms Rosamund Greensted for expert secretarial assistance. SC was in receipt of an MRC Training Fellowship.

\section{References}

' Ekbom K, Hed R, Kirstein L, Astrom K-E. Muscular affections in chronic alcoholism. Arch Neurol 1964;10:449-58.

${ }^{2}$ Cairns SR, Peters TJ. Micromethods for quantitative lipid analysis of human liver needle biopsy specimens. Clin Chim Acta 1983;127:373-82.

${ }^{3}$ Edwards R, Young A, Wiles M. Needle biopsy of skeletal muscle in the diagnosis of myopathy and the clinical study of muscle function and repair. $N$ Engl $J$ Med 1980;302:261-71.

4 Kapuscinki J, Skoczylas B. Simple rapid fluorometric method for DNA microassay. Anal Biochem 1977;83:252-7.

${ }^{5}$ Morrison WR, Smith LM. Preparation of fatty acid methyl esters and dimethylacetate from lipids with boron fluoride-methanol. J Lipid Res 1964;5:601-8.

- Hanid A, Slavin G, Mair W, Sowter C, Ward P, Webb J, Levi AJ. Fibre type changes in striated muscle of alcoholics. $J$ Clin Pathol 1981;34:991-5.

${ }^{7}$ Dubowitz V, Brooke M. Muscle biopsy, a modern approach. London: Saunders WB, 1973.

${ }^{8}$ Slavin G, Sowter C, Ward P, Paton K. Measurement of striated muscle fibre diameters using interactive computer-aided microscopy. J Clin Pathol 1982;35:1268-71.

${ }^{9}$ Brooke MH, Engel WK. The histographic analysis of human muscle biopsies with regard to fibre types. I. Adult male and female. Neurology (NY) 1969;19:221-33.

${ }^{10}$ Garrow JS. Treat obesity seriously: a clinical manual. Edinburgh: Churchill Livingstone: 1981.

${ }^{11}$ Ryan T, Joiner BL, Ryan B. Minitab reference manual University Park: Department of Statistics, Pennsylvania State University, USA, 1981

12 Israel Y. Cellular effects of alcohol; a review. J Stud Alcohol 1970;31:293-316.

${ }^{13}$ Eaton P, Steinberg D. Effects of medium fatty acid concentration, epinephrine and glucose on palmitate-1-C14 oxidation and incorporation into neutral lipids by skeletal muscle in vitro. J Lipid Res 1961;1:376-82.

${ }^{14}$ Evans JR, Opie LH, Shipp JC. Metabolism of palmitic acid in perfused rat heart. Am J Physiol 1963;205:766-70.

is Pritchard PH, Bowley M, Burditt SL, et al.The effects of acute ethanol feeding and of chronic benfluorex administration on the activities of some enzymes of glycolipid synthesis in rat liver and adipose tissue. Biochem J 1977;166:639-42.

${ }^{16}$ Klinkerfuss G, Bleisch V, Dioso MM, Perhoff GT. A spectrum of myopathy associated with alcoholism. II Light and electron microscopic observations. Ann Intern Med 1967;67:493.

${ }^{17}$ Martin FC, Levi AJ, Slavin G, Peters TJ. The selective reversible myopathy of alcoholism. Eur J Clin Invest 1982;12:153.

18 Cairns SR, Peters TJ. Biochemical assessment of hepatic lipid in chronic alcoholics, diabetics and control subjects: evidence for an alteration in hepatocyte membrane composition of alcoholics. Clin Sci 1983;64:24P.

${ }^{19}$ Lieber CS, De Carli LM. An experimental model of alcohol feeding and liver injury in the baboon. J Med Primatol 1974;3:153-63.

${ }^{20}$ Rubin E. Alcoholic myopathy in heart and skeletal muscle. $N$ Engl J Med 1979;301:28-33.

${ }^{21}$ Sarma JS, Ikeda S, Fischer R, Maruyama Y, Weishaar R, Bing RJ. Biochemical and contractile properties of heart muscle after prolonged alcohol administration. J Mol Cell Cardiol 1976;8:951-72.

${ }^{22}$ Rubin E, Beattie DS, Lieber CS. Effects of ethanol on the biogenesis of mitochondrial membranes and associated mitochondrial functions. Lab lnvest 1974;6:207-13. 
${ }^{23}$ Regan TJ, Khan MI, Ettinger PO, Haider B, Lyons MM, Oldewurtel HA. Myocardial function and lipid metabolism in the chronic alcoholic animal. J Clin Invest 1974;54:740-52.

${ }^{24}$ Puszkin S, Rubin E. Adenosine diphosphate effect on contractility of human skeletal muscle actomyosin: inhibition by ethanol and acetaldehyde. Science 1975;188:1319-20.

${ }^{25}$ Perkoff ET. Alcoholic myopathy. Ann Rev Med 1971;22:12532.

${ }^{26}$ Williams JW, Tada M, Katz AM, et al. Effect of ethanol and acetaldehyde on the $\left(\mathrm{Na}^{+}, \mathrm{K}^{+}\right)$-activated adenosine triphos- phatase activity of cardiac plasma membranes. Biochem $\stackrel{\stackrel{0}{\vec{\sigma}}}{0}$ Pharmacol 1975;24:27-32.

${ }^{27}$ Farias RN, Bloj B, Morero RD, Sineriz F, Trucco RF. Regula- $\overrightarrow{\bar{F}}$ tion of allosteric membrane-bound enzymes through changes in membrane lipid composition. Biochim Biophys ActaO 1975; 415:231-51.

Requests for reprints to: Professor TJ Peters, Division of Clinical Cell Biology, MRC Clinical Research Centre, Watford Road, Harrow, Middlesex HA1 3UJ, England. 